\title{
Mass Gathering (Hajj) Clinical Pharmacy Services: New Initiative in Saudi Arabia
}

Yousef Ahmed Alomi* iD, Critical Care Clinical Pharmacists, TPN Clinical Pharmacist, Freelancer Business Planner, Content Editor and Data Analyst, Riyadh, Saudi Arabia.

Nezar Adnan Yahya Khayat, Bsc. Pharm

Medication Safety Officer, Pharmaceutical Care Administration, Makkah Medical Affairs Region, Makkah, Saudi Arabia.

Yasir Abdulraheem Bamagaus, Bsc. Pharm Regional General Manager, Pharmaceutical Care Administration, Makkah Medical Affairs Region, Makkah, Saudi Arabia.

Sultan Mesfer Aljumayi, Bsc. Pharm

Staff Pharmacist, Pharmaceutical Care Administration, Makkah Medical Affairs Region, Makkah, Saudi Arabia.

Hani Mohammed Ali Jumah, Pharm D

Staff Pharmacist, Pharmaceutical Care Administration, Makkah Medical Affairs Region, Makkah, Saudi Arabia.

Ahmad M. AlKharoby, MD

Assistant General Manager for assistant medical affiars, Makkah Medical Affairs Region, Makkah, Saudi Arabia.

Wael H. Motair, MD

General Manager, Makkah Medical Affairs

Region, Makkah, Saudi Arabia.

\section{Correspondence:}

Dr. Yousef Ahmed Alomi, (BSc. Pharm, MSc. Clin Pharm, BCPS, BCNSP, DiBA, CDE)

Critical Care Clinical Pharmacists, TPN Clinical Pharmacist, Freelancer Business Planner, Content Editor and Data Analyst, P.O. BOX 100, Riyadh-11392, Riyadh, Saudi Arabia.

Phone no: +966504417712

E-mail:yalomi@gmail.com

Received: 16-09-2019;

Accepted: 13-12-2019

Copyright: (c) the author(s), publisher and licensee International Journal of Pharmacology and Clinical Sciences. This is an openaccess article distributed under the terms of the Creative Commons Attribution NonCommercial License, which permits unrestricted non-commercial use, distribution, and reproduction in any medium, provided the original work is properly cited.

This is an open access article distributed under the terms of the Creative Commons Attribution-NonCommercial-ShareAlike 4.0 License

Access this article online

\begin{tabular}{|c|c|}
\hline & www.ijpcs.net \\
\hline & DOI: \\
\hline
\end{tabular}

\begin{abstract}
Objective: To declare the clinical pharmacy services during the mass gathering hajj period as a new initiative in the Kingdom of Saudi Arabia. Methods: It is a new initiative project drove by national mass gathering pharmaceutical programs. The projects drove the mass gathering medicine guidelines and the international business model, pharmacy project guidelines project management institution guidelines of a new project. The initiative project is written through project management professionals and consisted of several parts, including the initial phase, the planning phase, the execution phase and the monitoring and controlling phase. Results: The mass gathering clinical pharmacy services with a defined vision, mission and goals. The services had multiple benefits, including clinical and economical on the healthcare system, as described in the review. The continuation of the services assured by risk management elements description. Moreover, the monitoring and controlling of the projects as illustrated. The transition to operation project, though closing project stage illustrated in the analysis. Conclusion: The clinical pharmacy services during the mass gathering hajj period is a new initiative project in the mass gathering medicine. Multiple clinical pharmacy services can be started during a mass gathering with an emphasison decrease morbidity and mortality; it is highly recommended in the Kingdom of Saudi Arabia.

Keywords: Mass gathering, Hajj, Clinical pharmacy, Initiative, Saudi Arabia.
\end{abstract}

\section{INTRODUCTION}

Over the past several years, clinical pharmacy services were expanded in the Kingdom of Saudi Arabia. ${ }^{[1]}$ The number of pharmacists and clinical pharmacists are increased. Also, the types of clinical pharmacy services with different quantities and quality increased in hospitals and primary healthcare centers. ${ }^{[1,2]}$ However, the clinical pharmacy services not included during the mass gathering hajj period. The author and his colleges recommended to start the clinical pharmacy services within mass gathering hajj period and increase the number of clinical pharmacists and clinical pharmacy technicians as a helper with high demand emphasis especially. ${ }^{[3,4]}$ Another investigation suggested starting clinical activities during mass gathering haij period. ${ }^{[5]}$ The role of the clinical pharmacist is potential as a general practice and emphasis with mass gathering hajj with an infinite number of pilgrims and hopefully to decrease the morbidity and mortality resemble other locations over all the world. ${ }^{[6]}$ The involvement of clinical pharmacy services during mass gathering hajj is a new initiative recommended which not familiar to existed in other countries. The aim of this project is to explore the mass gathering of clinical pharmacy services in the Kingdom of Saudi Arabia.

\section{METHOD OF DEVELOPMENT OF THE PROJECT}

It is a new initiative project drove by national mass gathering pharmaceutical programs. The task force team of mass gathering hajj pharmacy projects formulated and consisted of from an author's expert in the mass gathering hajj. The committee unitized and drove the mass gathering medicine guidelines and from the textbook and international literature about mass gathering clinical pharmacy written by utilizing the international business model, pharmacy project guidelines project management institution guidelines of a new project. ${ }^{[7-10]}$ The mass gathering clinical pharmacy project is written through project management professionals and consisted of several parts, including the initial phase, the planning phase, the execution phase and the monitoring and controlling phase.

\section{Initial Phase}

\section{Assessment Needs}

One of the vital healthcare services provided for the pilgrims was the pharmacy department. The pharmacist implemented pharmaceutical care for several years back. During the mass gathering hajj period, the demand is very high to implement the concept of pharmaceutical care to provide the best medications with reach beneficial clinical outcomes and without drug-related problems, especially with the mass gathering is required. However, most of the governmental or private organizations did not offer the clinical pharmacy services with mass gathering hajj period. 


\section{Market Analysis}

The pharmacy indicators had been used today in most hospitals. It required from higher administration of the healthcare system and planner at the Ministry of Health and other healthcare organizations overall the year in the kingdom of Saudi Arabia. However, the pharmacy indicators during mass gathering hajj not fully implemented yet in most healthcare institutions. The national pharmacy indicators during mass gathering hajj period are highly recommended to assess the pharmacy services and plan for the future of pharmaceutical care services during a mass gathering hajj period in the kingdom of Saudi Arabia.

\section{SWOT Analysis}

The most method of analysis of the new project was SWOT analysis. The strength point of this project is to declare the role of pharmacists during mass gathering hajj period, prevent drug misadventures to the pilgrims, decrease accumulative unnecessary economic burden on the healthcare system. The weak points of the project were the workforces of clinical pharmacists not available; the different special $\neg$ ties of clinical pharmacy not available, some-times it is hard to implement some clinical activities during the mass gathering. Several opportunities can be utilized to implement the project, for instant, the international and local quality management standard implementation of all government and private hospitals, the new vision 2030 in Saudi Arabia. The thread points of the project are maybe national mass gathering hajj committee reject the project and the financial support for clinical pharmacists not existed.

\section{Planning Phase}

\section{Scope of the Project}

The scope of the program to deliver clinical pharmacy services with emphasis to infectious disease clinical pharmacy, emergency clinical pharmacy, critical care clinical pharmacy, ambulatory care clinical pharmacy and other demand clinical pharmacy services to all pilgrims the holy cities of Makkah and Almadina area during mass gathering hajj period every year.

\section{Vision, Missions and Goals}

The vision to reach best and high-quality clinical pharmacy services during mass gathering hajj in the kingdom of Saudi Arabia. The mission to provide clinical pharmacy services to all visitors and pilgrims during mass gathering hajj over all the year. The objective of the program to provide high-quality pharmaceutical care to the pilgrims, to prevent drug-related morbidity and mortality of pilgrims visiting the holy cit- ies, to improve patient care to the pilgrims, for avoiding the unnecessary economic burden of mass gathering hajj healthcare system.

\section{Project Description}

$\checkmark$ Each year the mass gathering hajj committee should announce about clinical pharmacy specialties demand during mass gathering hajj period.

$\checkmark$ The announcement arrangement with the pharmacy workforce in Makkah and Almadina regions.

$\checkmark$ The mass gathering committee should assign clinical pharmacist supervisor in Makkah and Almadina regions.

$\checkmark$ The clinical pharmacy supervisor should distribute each clinical pharmacy specialist for each hospital or primary healthcare centers.

$\checkmark$ The pharmacy director of each hospital should receive the clinical pharmacist and make orientation for him and involvement with his medical team.

$\checkmark$ The medical team member should give the new clinical pharmacist orientation about their system during a mass gathering hajj period.

$\checkmark$ The clinical pharmacist should, according to their specialties, with the best pharmaceutical care providers.

$\checkmark$ The clinical should document the pharmacist intervention, medication errors, drug information inquiries and patients counseling with a clinical and economic impact electronically.

$\checkmark$ The final report should to the clinical pharmacy supervisor by the end of the hajj period.

$\checkmark$ The clinical pharmacy supervisor should send the final all reports of clinical pharmacists during mass gathering hajj period to the higher committee of mass gathering hajj committee and discussed their recommendations for next year.

$\checkmark$ Plan schedule management.

\section{Planning Cost Management}

The projected demand for the financial budget to cover the expenses of project teams, the salary of a clinical pharmacist, Education courses for the clinical pharmacist and pharmacy staff and some material need for patients about their medications.

\section{Executing Phase \\ Management Team}

The management teams, each may be led by a higher administration team consisted of expert clinical pharmacists within mass gathering hajj. Besides, the clinical pharmacist from different regions with a different specialty with an emphasis on critical care, emergency and infectious diseases. The team takes care of the responsibility for the program implementation and follow up the outcomes of the program. Besides, the team resolves any discrepancies during the program application.

\section{Education and Training}

One essential tool to implement the project is education and training. Many courses should be delivered to the clinical pharmacist on their specialties during the mass gathering hajj period. Besides, other training should be conducted for pharmacy staff and pharmacy technician. The education courses can be regular or online with electronic materials. The courses should short courses for updating knowledge or long courses, including residency training over one year with an emphasis on mass gathering hajj activities. Another education for healthcare providers about the project that's including physicians and nurses and management team members and all administration committees as orientation courses.

\section{Monitoring and Controlling Phase Project Total Quality Management}

There are multiple tools of quality management used for the new initiative project implementation process. One of the current tools used and called balance scored cards. The BSC system measures four types of key performance indicators with the included customer, finance, internal process, education and innovation. The assessment of clinical pharmacy services during the mass gathering hajj period is an example of internal process key performance indicators. The measures of clinical outcomes of clinical pharmacy services during mass gathering hajj time is types of education and competency. The measurement of cost efficiency of clinical pharmacy services during mass gathering hajj period is another example of financial types, while the patient's satisfaction with clinical pharmacy services or pharmacy staff and healthcare provider's satisfaction of clinical pharmacy services during mass gathering hajj activities is customer types of key performance indicators.

\section{Risk Management}

There are six types of risks in the project that's including the budget risks, scope risks, personal risks, schedule risk, technical risks and quality risks. The project may be exposed to risks such as quality, personal and risks. The project might have a budget risk due to no availability of the budget for bringing new expert clinical pharmacist or education and training for postgraduate or residency programs. The project may be exposed to personnel risks such as shortage of 
expert specialized clinical pharmacy staff. The project might be exposed to quality risks due to the non-qualified clinical pharmacist and expert on practice with mass gathering hajj activities or not implemented KPI. The project might experience technical risks such as the non-availability of the electronic references of clinical pharmacy practice during mass gathering hajj period.

\section{Closing of the Project}

The mass gathering hajj period clinical pharmacy services at all healthcare hospitals and primary healthcare centers are required services to drug-related problems with costeffective drug therapy in the Kingdom of Saudi Arabia. The services should continue with the involvement of the country's clinical pharmacy and related committees. The mass gathering hajj clinical pharmacy Education and training short and long residency should be conducted regularly. Further, more clinical pharmacy service is Specialty expanded in the future. Annual celebration with the involving clinical pharmacists during mass gathering hajj period of the project is recommended.

\section{ACKNOWLEDGEMENT}

None.

\section{CONFLICT OF INTEREST}

The authors declare no conflict of interest.

\section{ABBREVIATIONS}

MOH: Ministry of Health; KSA: Kingdom of Saudi Arabia; ASHP: American Society of Health-System Pharmacists; SWOT: Strengths, Weaknesses, Opportunities and Threats; BSC: Balance Scored Cards; MSO: Medication Safety Officer.

\section{REFERENCES}

1. Alomi YA, Alghamdi SJ, Alattyh RA. National survey of pharmacy practice at $\mathrm{MOH}$ Hospitals in Saudi Arabia 2016-2017: Clinical Pharmacy Services. J Pharm Pr Community Med. 2018;4(1):1S-8S.

2. Saudi Ministry of Health. Health Statistical Year Book 2017. Ministry of Health Portal, Kingdom of Saudi Arabia. 2017. Available from: https://www. moh.gov.sa/en/Ministry/Statistics/Pages/default. aspx.

3. Alomi YA, Khayat NA, Al-Hennawi KI. Clinical pharmacy services and workforce requirements at ministry of health hospitals during ten years mass gathering hajj (2006-2015) In Makah And Al-Medina Regions, Saudi Arabia. Value Heal. 2017;20(9): A674.

4. Alomi YA, Alhennawi K, Khayayt N. Clinical pharmacy technician activities and workforce requirements at $\mathrm{MOH}$ hospitals during ten years mass gathering hajj (2006-2015) in Makah and Al-Medina Regions, Saudi Arabia. J Pharm Pract Community Med. 2017;3(4s):S48-55.

5. Alomi YA, Alhennawi K, Khayayt N. Clinical pharmacy services and human resources requirements at $\mathrm{MOH}$ primary healthcare centers during ten years mass gathering hajj (2006-2015) in Makah and Al-Medina Regions, Saudi Arabia. J Pharm Pract Community Med. 2017;3(4s):s84-9.

6. Bond CA, Raehl CL. Clinical pharmacy services, pharmacy staffing and hospital mortality rates. Pharmacotherapy. 2007;27(4):481-93.

7. McDonough R. Writing a business plan for a new pharmacy service. The Dynamics of Pharmaceutical Care: Enriching Patients' Health. 2010;23.

8. Harris IM, Baker E, Berry TM, et al. Developing a business-practice model for pharmacy services in ambulatory settings. Pharmacotherapy. 2008;28(2):7e-34e

9. Sachdev G. Sustainable business models: Systematic approach toward successful ambulatory care pharmacy practice. Am J Heal Pharm. 2014;71(16):1366-74.

10. PMBOK Guide. A guide to the project management body of knowledge. Sixth Edition. Project Management Institute, Inc. 2017. 